\title{
PENGARUH PRICE DISCOUNT DAN STRATEGI LOKASI TERHADAP IMPULSE BUYING PADA SWALAYAN ALFAMART KOTA BAKTI KABUPATEN PIDIE
}

\author{
Nyak Umar ${ }^{(1)}$, Ismawati ${ }^{(2)}$ \\ Program Studi Manajemen Fakultas Ekonomi Universitas Jabal Ghafur \\ Email :
}

\begin{abstract}
ABSTRAK
Penelitian ini berjudul Pengaruh Price Discount dan Strategi Lokasi terhadap Impulse Buying pada Swalayan Alfamart Kota Bakti Kabupaten Pidie". Penelitian bertujuan untuk mengetahui pengaruh price discount dan strategi lokasi serta variabel dominan yang berpengaruh terhadap Impulse Buying pada Swalayan Alfamart Kota Bakti Kabupaten Pidie. Penelitian ini dilakukan di Swalayan Alfamart Kota Bakti Kabupaten Pidie yang berlokasi di Pasar Kota Bakti, Kecamatan Sakti, Kabupaten Pidie. Populasi penelitian adalah seluruh konsumen yang melakukan pembelian pada Swalayan Alfamart Kota Bakti Kecamatan Sakti Kabupaten Pidie. Sampel diambil sebanyak 96 orang. Metode pengumpulan data dilakukan melalui observasi, studi pustaka, dan kuesioner. Dalam menjelaskan hubungan antara variabel independen dengan dependen, model yang digunakan adalah model regresi berganda, yang dapat dinyatakan sebagai berikut : $\hat{Y}=a+b_{1} X_{1}+b_{2} X_{2}+$ e. Berdasarkan output SPSS diperoleh model regresi berganda dalam bentuk persamaan sebagai berikut: $\mathrm{Y}=$ $2.024+0.339 \mathrm{X}_{1}+0.174 \mathrm{X}_{2}$, dimana Variabel Discount Price $\left(\mathrm{X}_{1}\right)$ mempunyai pengaruh yang dominan terhadap Impulse Buying pada Swalayan Alfamart Kota Bakti. Hubungan antara variabel Discount Price $\left(\mathrm{X}_{1}\right)$ dan Strategi Lokasi $\left(\mathrm{X}_{2}\right)$ terhadap Impulse Buying (Y) pada Swalayan Alfamart Kota Bakti diperoleh nilai indeks korelasi sebesar $62.8 \%$ yang menunjukkan adanya hubungan kuat.Indeks determinasi masing-masing variabel Discount Price $\left(\mathrm{X}_{1}\right)$ dan Strategi Lokasi $\left(\mathrm{X}_{2}\right)$ terhadap variabel Impulse Buying (Y) diperoleh sebesar $39.5 \%$ yang berarti bahwa varisi variabel bebas dapat menjelaskan variabel tidak bebas sebesar $39.5 \%$ sedangkan selebihnya yaitu $60.5 \%$ dipengaruhi oleh variabel lain yang tidak diteliti dalam penelitian ini.Variabel Discount Price $\left(\mathrm{X}_{1}\right)$ dan Strategi Lokasi $\left(\mathrm{X}_{2}\right)$ secara simultan berpengaruh secara signifikan terhadap Impulse Buying pada Swalayan Alfamart Kota Bakti. Hal ini ditunjukkan oleh nilai $F_{\text {hitung }} 30.336>F_{\text {tabel }}$ 3.094.Variabel Discount Price $\left(\mathrm{X}_{1}\right)$ secara parsial berpengaruh signifikan terhadap Impulse Buying pada Swalayan Alfamart Kota Bakti karena nilai $t_{\text {hitung }} 5.780>t_{\text {tabel }}$ 1.986.Variabel Strategi Lokasi $\left(\mathrm{X}_{2}\right)$ secara parsial berpengaruh signifikan terhadap Impulse Buying pada Swalayan Alfamart Kota Bakti. Hal ini ditunjukkan oleh nilai $\mathrm{t}_{\text {hitung }} 3.007>\mathrm{t}_{\text {tabel }} 1.986$.
\end{abstract}

\section{Kata Kunci : Price Discount, Strategi Lokasi, Impulse Buying}

\section{PENDAHULUAN}

1. Latar Belakang

Persaingan untuk

memperebutkan calon pelanggan dan juga mempertahankan langganan yang sudah ada merupakan tantangan yang semakin besar dan harus dihadapi oleh perusahaan dalam memasarkan produknya. Perusahaan harus meningkatkan penjualannya secara 
signifikan agar perusahaan tetap eksis, bahkan lebih jauh lagi perusahaan harus bisa lebih maju. Untuk meningkatkan volume atau jumlah penjualan dari suatu produk yang ditawarkan, maka tidak bisa terlepas dari pemasaran atau marketing.

Perilaku pembelian yang tidak direncanakan atau impulse buying merupakan sesuatu yang menarik bagi produsen maupun pengecer, karena merupakan pangsa pasar terbesar dalam pasar modern. Namun seiring dengan perkembangan zaman, produk yang dipilih atau dibeli oleh seorang konsumen seringkali tidak lagi menjadi produk kebutuhan (needs) konsumen melainkan sudah mengarah pada apa yang diinginkan konsumen (wants) sehingga kemungkinan terjadinya pembelian implusif (impulse buying) sangat besar adanya.

Price discount merupakan promosi penjualan yang paling banyak digunakan untuk meningkatkan impulse buying konsumen. Discount atau potongan harga merupakan salah satu bentuk dari promosi penjualan yang sering diterapkan oleh pemasar yang lebih ditujukan kepada konsumen akhir.

Lokasi merupakan salah satu faktor dari situasional yang ikut berpengaruh pada keputusan pembelian karena lokasi berhubungan langsung dengan pembeli atau konsumen atau dengan kata lain lokasi juga merupakan tempat produsen menyalurkan produknya kepada konsumen. Banyak perusahaan yang secara sengaja memilih lokasi operasionalnya dekat dengan konsumen karena kedekatan dengan pasar merupakan faktor utama keberhasilan usaha mereka.

\section{Tujuan Penelitian}

Penelitian ini bertujuan untuk mengetahui pengaruh price discount dan strategi lokasi serta variabel dominan terhadap impulse buying pada Swalayan Alfamart Kota Bakti Kabupaten Pidie

\section{METODE PENELITIAN}

\section{Lokasi Penelitian}

Penelitian ini dilakukan di Swalayan Alfamart Kota Bakti Kabupaten Pidie yang berlokasi di Pasar Kota Bakti, Kecamatan Sakti, Kabupaten Pidie. Ruang lingkup penelitian ini dibatasi pada deskripsi berbagai hal yang berkaitan dengan perilaku impulse buying pada Swalayan Alfamart Kota Bakti akibat adanya price discount, dan lokasi toko.

\section{Populasi dan Sampel}

Populasi penelitian ini adalah seluruh konsumen yang melakukan pembelian pada Swalayan Alfamart Kota Bakti Kecamatan Sakti Kabupaten Pidie. Sampel adalah bagian dari jumlah dan karakteristik yang dimiliki oleh populasi tersebut (Sugiyono, 2011:118). Sampel yang dipilih dalam penelitian ini menggunakan rumus unknown population menurut Slovin sehingga jumlah sampel penelitian yang diambil adalah sebanyak 96 orang.

\section{Metode Pengumpulan Data}

Metode pengumpulan data yang digunakan dalam penelitian ini antara lain: observasi, studi pustaka, dan kuesioner. Kuesioner yang digunakan dalam penelitian ini adalah kuesioner dengan model Skala Likert.

\section{Metode Analisis Data \\ a. Uji Validitas}

Uji validitas digunakan untuk mengukur sah atau valid tidaknya suatu kuesioner. Suatu kuesioner dikatakan valid jika pertanyaan pada kuesioner mampu mengungkapkan sesuatu yang akan diukur oleh kuesioner tersebut (Ghozali, 2013). 


\section{b. Uji Reliabilitas}

Uji Reliabilitas adalah alat untuk mengukur suatu koesioner yang merupakan indikator dari variabel atau konstruk. Suatu kuesioner dikatakan reliabel atau andal jika jawaban seseorang terhadap pernyataan adalah konsisten atau stabil dari waktu ke waktu (Ghozali, 2013).

\section{c. Uji Asumsi Klasik}

1). Uji Normalitas

Uji normalitas bertujuan untuk menguji apakah dalam model regresi, variabel pengganggu atau residual memiliki distribusi normal (Ghozali, 2013).

\section{2). Uji Multikolinieritas}

Uji multikolinieritas bertujuan untuk menguji apakah model regresi ditemukan adanya korelasi antar variabel bebas (independen). Model regresi yang baik seharusnya tidak terjadi korelasi di antara variabel independen (Ghozali, 2013).

\section{3). Uji Heteroskedastisitas}

Uji heteroskedastisitas bertujuan menguji apakah dalam model regresi terjadi ketidaksamaan variance dari residual satu pengamatan ke pengamatan yang lain. Model regresi yang baik adalah yang tidak terjadi heteroskedastisitas (Ghozali, 2013).

\section{4). Uji Autokorelasi}

Uji autokorelasi merupakan korelasi pada tempat yang berdekatan datanya yaitu cross sectional. Autokorelasi merupakan korelasi time series (lebih menekankan pada dua data penelitian berupa data rentetan waktu). Cara mendeteksi ada tidaknya gejala autokorelasi adalah dengan menggunakan nilai DW (Durbin Watson) dengan kriteria pengambilan jika D - W sama dengan 2, maka tidak terjadi autokorelasi sempurna sebagai rule of tumb (aturan ringkas), jika nilai D - W diantara 1,5 - 2,5 maka tidak mengalami gejala autokorelasi

(Ghozali, 2013).

\section{Uji Hipotesis}

\section{Berganda}

a. Analisis Regresi Linear

Analisis regresi linear berganda digunakan untuk mengetahui pengaruh price discount, strategi lokasi, dan sistem antrian terhadap impulse buying. Model persamaan regresi linier berganda yang digunakan adalah sebagai berikut (Sugiyono, 2014):

$\mathrm{Y}=\mathrm{a}+\mathrm{b}_{1} \cdot \mathrm{X}_{1}+\mathrm{b}_{2} \cdot \mathrm{X}_{2}+\mathrm{e}$

\section{b. Koefisien Determinasi $\left(\mathbf{R}^{2}\right)$}

Koefisien regresi digunakan untuk mengukur seberapa jauh kemampuan model dalam menerangkan variasi variabel terikat. Nilai koefisien determinasi adalah antara nol dan satu.

\section{c. Uji t (Uji Parsial)}

Uji t digunakan untuk menguji signifikansi hubungan antara variabel $\mathrm{X}$ dan variabel $\mathrm{Y}$ secara parsial atau dapat dikatakan uji t pada dasarnya menunjukan seberapa jauh satu variabel independen secara individual dalam menerangkan variasi-variasi dependen (Ghozali, 2013).

\section{d. Uji F}

Uji $F$ pada dasarnya menunjukkan apakah semua variabel bebas yang dimasukkan dalam model mempunyai pengaruh secara bersamasama terhadap variabel terikat (Ghozali, 2013).

\section{HASIL PENELITIAN DAN PEMBAHASAN}

\section{Uji Validitas dan Reliabilitas}

\section{$1.1 \quad$ Uji Validitas}

Pengujian validitas terhadap butir-butir pertanyaan yang diajukan pada kuisioner dilakukan secara statistik dengan menggunakan metode korelasi product moment. Hasil uji korelasi product moment ditampilkan pada tabel sebagai berikut: 
Tabel 1 Hasil Uji Validitas

\begin{tabular}{|c|c|c|c|c|}
\hline Variabel & Pertanyaan & $\begin{array}{c}\text { Koefisien } \\
\text { Korelasi }\end{array}$ & $\begin{array}{c}\text { Nilai Kritis }=5 \% \\
(45)\end{array}$ & Ket \\
\hline \multirow[t]{3}{*}{$\mathrm{X}_{1}$} & $\mathrm{X} 1.1$ & 0.658 & 0,199 & Valid \\
\hline & $\mathrm{X} 1.2$ & 0.603 & 0,199 & Valid \\
\hline & $\mathrm{X} 1.3$ & 0.804 & 0,199 & Valid \\
\hline \multirow[t]{3}{*}{$\mathrm{X}_{2}$} & $\mathrm{X} 4$ & 0.767 & 0,199 & Valid \\
\hline & $\mathrm{X} 5$ & 0.779 & 0,199 & Valid \\
\hline & $\mathrm{X} 6$ & 0.790 & 0,199 & Valid \\
\hline \multirow[t]{7}{*}{$\mathrm{Y}$} & $\mathrm{Y} 1$ & 0.614 & 0,199 & Valid \\
\hline & $\mathrm{Y} 2$ & 0.201 & 0,199 & Valid \\
\hline & $\mathrm{Y} 3$ & 0.679 & 0,199 & Valid \\
\hline & $\mathrm{Y} 4$ & 0.820 & 0,199 & Valid \\
\hline & Y5 & 0.792 & 0,199 & Valid \\
\hline & Y6 & 0.286 & 0,199 & Valid \\
\hline & Y7 & 0.332 & 0,199 & Valid \\
\hline
\end{tabular}

Sumber : Data primer, diolah, 2020

Data pada Tabel 1 di atas dapat dijelaskan bahwa nilai $\mathrm{r}_{\text {hitung }}$ untuk masing-masing item indikator variabel lebih besar dari $r_{\text {tabel }}(0.199)$ sehingga butir-butir kuesioner dalam penelitian ini dinyatakan valid. Hal ini berarti seluruh butir pertanyaan pada kuesioner dapat digunakan sebagai instrumen penelitian.

\subsection{Uji Reliabilitas}

Nilai koefisien reliabilitas (koefisien alpha) bervariasi mulai dari 0 (nol) sampai dengan 1 (satu), tetapi apabila nilai alphanya $\leq 0.60$ memberi indikasi bahwa alat ukur tersebut kurang kehandalannya. Hasil pengujian reliablitas variabel penelitian ini ditunjukkan pada Tabel berikut.

Tabel 2

Reliabilitas Variabel Penelitian

\begin{tabular}{|c|c|c|c|c|}
\hline No & Variabel & $\begin{array}{c}\text { Item } \\
\text { Variabel }\end{array}$ & $\begin{array}{c}\text { Nilai } \\
\text { Alpha }\end{array}$ & Kehandalan \\
\hline 1 & $\begin{array}{c}\text { Discount Price } \\
\left(\mathrm{X}_{1}\right)\end{array}$ & 3 & 0.728 & Handal \\
\hline 2 & $\begin{array}{c}\text { Strategi } \\
\left.\text { Lokasi( } \mathrm{X}_{2}\right)\end{array}$ & 3 & 0.829 & Handal \\
\hline 3 & $\begin{array}{c}\text { Impulse Buying } \\
(\mathrm{Y})\end{array}$ & 7 & 0.646 & Handal \\
\hline
\end{tabular}

Sumber : Data Primer Diolah (2020)
Data pada Tabel 2 dapat dijelaskan bahwa nilai koefisien alpha untuk masing-masing variabel penelitian yaitu variabel Discount Price $\left(\mathrm{X}_{1}\right)$ sebesar 0.728 , variabel Strategi Lokasi $\left(\mathrm{X}_{2}\right)$ sebesar 0.829, dan nilai alpha variabel Impulse Buying (Y) sebesar 0.646 . Masing-masing variabel penelitian memiliki nilai koefisien alpha lebih dari 0.60 sehingga memenuhi syarat reliabilitas atau kuesioner reliabel sebagai instrumen penelitian.

\subsection{Analisis Pengujian Asumsi Klasik}

\subsubsection{Uji Normalitas}

Uji normalitas digunakan untuk menguji normal atau tidaknya data sampel yang diambil. Residual variabel yang terdistribusi normal terletak di sekitar garis horizontal (tidak terpisah jauh dari garis diagonal). Berdasarkan P-Plot pada lampiran menunjukkan sebaran standardized residual berada dalam kisaran garis diagonal. Seperti terlihat pada gambar berikut :

\section{Gambar 1 P-Plot Uji Normalitas}

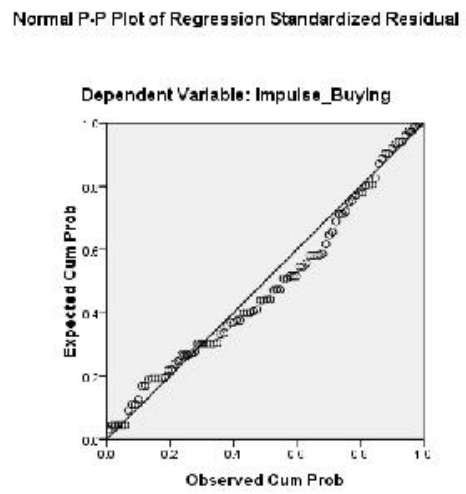

\subsubsection{Uji Multikolinearitas} Hasil pengujian multikolonearitas variabel penelitian ditunjukkan pada tabel berikut : 
Tabel 3

Nilai VIF Variabel Bebas

\begin{tabular}{|l|c|c|}
\hline \multicolumn{1}{|c|}{$\begin{array}{c}\text { Variabel } \\
\text { Bebas }\end{array}$} & VIF & Keterangan \\
\hline $\begin{array}{l}\text { Variabel } \\
\text { Discount } \\
\text { Price }\left(\mathrm{X}_{1}\right)\end{array}$ & 1.124 & $\begin{array}{c}\text { Non } \\
\text { Multikolinearitas }\end{array}$ \\
\hline $\begin{array}{l}\text { Variabel } \\
\text { Strategi } \\
\text { Lokasi }\left(\mathrm{X}_{2}\right)\end{array}$ & 1.124 & $\begin{array}{c}\text { Non } \\
\text { Multikolinearitas }\end{array}$ \\
\hline
\end{tabular}

Sumber :Data primer, diolah, 2020

Tabel 3 di atas dapat dijelaskan bahwa nilai VIF untuk variabel bebas dalam penelitian ini yaitu 1,124 kurang dari 10, hal ini berarti data variabel bebas tidak mengandung variabel pengganggu yang dapat mengurangi validitas hasil penelitian (nonmultikolinearitas).

\subsubsection{Uji Heteroskedastisitas}

Hasil pengolahan data menunujukkan grafik scatterplot seperti terlihat sebagai berikut :

\section{Gambar 2 \\ GrafikUji Heteroskedastisitas}

Scatterplot

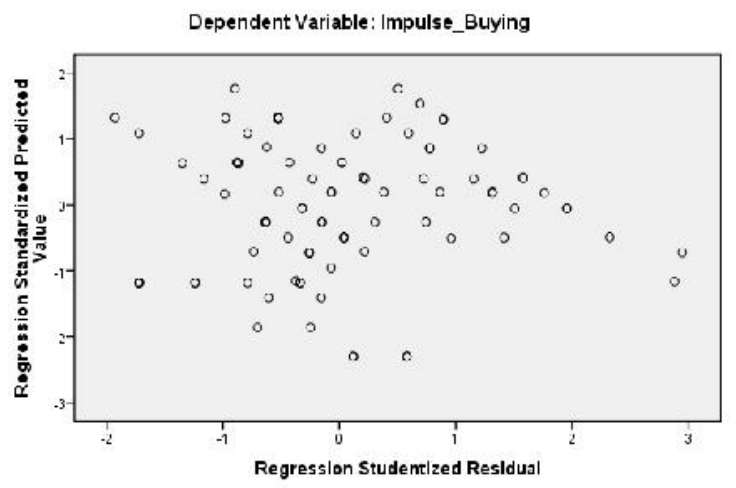

Berdasarkan grafik scatterplot yang ditunjukkan di atas terlihat tidak memiliki pola tertentu yang teratur (bergelombang, melebar kemudian menyempit), dengan demikian dapat diartikan tidak terjadi gejala heteroskedastisitas.

\section{Pembahasan}

Hasil analisis data variabel penelitian dengan menggunakan software SPSS versi 21.0 dapat dilihat pada Tabel berikut ini:

Tabel 4.

Pengaruh Variabel Discount Price dan Strategi Lokasi terhadap Impulse Buying pada Swalayan Alfamart Kota Bakti

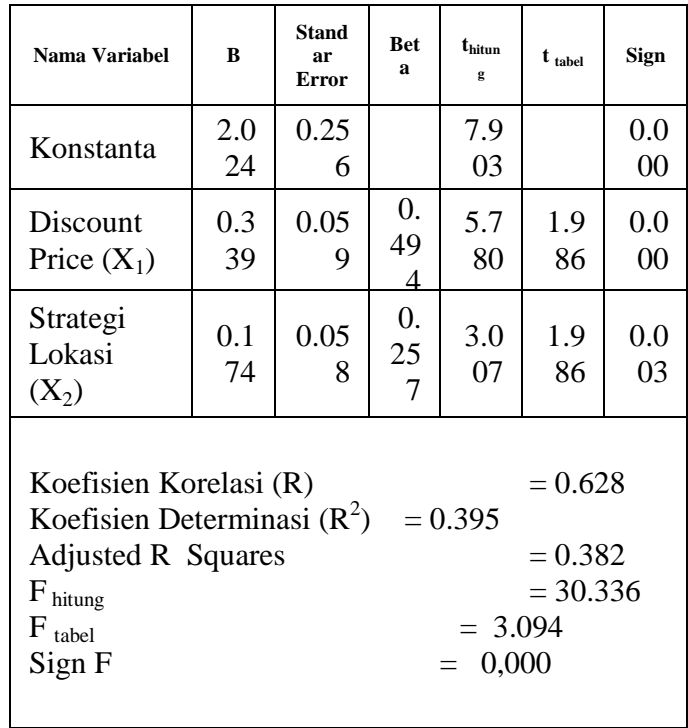

Sumber: Data primer, diolah, 2020

Tabel 4 di atas dapat dijelaskan bahwa hasil analisis data menggunakan program software SPSS versi 21.0 diperoleh model persamaan regresi linear berganda sebagai berikut: $\mathrm{Y}=2.024+0.339 \mathrm{X}_{1}+$ $0.174 \mathrm{X}_{2}$

Berdasarkan hasil analisis di atas dapat disimpulkan bahwa dari kedua variabel yang diteliti, ternyata variabel Discount Price $\left(\mathrm{X}_{1}\right)$ mempunyai pengaruh yang dominan terhadap Impulse Buying pada Swalayan Alfamart Kota Bakti.

Hubungan antara variabel Discount Price $\left(\mathrm{X}_{1}\right)$ dan Strategi Lokasi $\left(\mathrm{X}_{2}\right)$ terhadap Impulse Buying (Y) pada Swalayan Alfamart Kota 
Bakti diperoleh nilai indeks korelasi sebesar $62.8 \%$.

Indeks determinasi diperoleh sebesar $39.5 \%$ yang berarti bahwa varisi variabel bebas dapat menjelaskan variabel tidak bebas sebesar $39.5 \%$ sedangkan selebihnya yaitu $60.5 \%$ dipengaruhi oleh variabel lain yang tidak diteliti dalam penelitian ini.

Hasil pengujian secara simultan diperoleh nilai $F_{\text {hitung }} 30.336$ $>\mathrm{F}_{\text {tabel }} 3.094$, menunjukkan bahwa hasil perhitungan ini menerima hipotesis alternatif (Ha) dan menolak hipotesis nol (Ho), artinya bahwa variabel Discount Price $\left(\mathrm{X}_{1}\right)$ dan Strategi Lokasi $\left(\mathrm{X}_{2}\right)$ secara bersamasama berpengaruh secara signifikan terhadap Impulse Buying pada Swalayan Alfamart Kota Bakti.

Variabel Discount Price $\left(\mathrm{X}_{1}\right)$ diperoleh nilai $t_{\text {hitung }} 5.780>\mathrm{t}_{\text {tabel }}$ 1.986, dengan demikian hipotesis nol (Ho) ditolak dan hipotesis alternatif (Ha) diterima. Dari hasil uji t ini dapat disimpulkan bahwa variabel Discount Price $\left(\mathrm{X}_{1}\right)$ secara parsial berpengaruh signifikan terhadap Impulse Buying pada Swalayan Alfamart Kota Bakti.

Variabel Strategi Lokasi $\left(\mathrm{X}_{2}\right)$ diperoleh nilai $t_{\text {hitung }} 3.007>t_{\text {tabel }}$ 1.986, dengan demikian hipotesis nol (Ho) ditolak dan hipotesis alternatif (Ha) diterima. Dari hasil uji t ini dapat disimpulkan bahwa variabel Strategi Lokasi secara parsial berpengaruh signifikan terhadap Impulse Buying pada Swalayan Alfamart Kota Bakti.

\section{KESIMPULAN DAN SARAN}

\section{Kesimpulan}

Hasil analisis data tentang Pengaruh Discount Price dan Strategi Lokasi terhadap Impulse Buying pada Swalayan Alfamart Kota Bakti diperoleh model persamaan regresi linear berganda sebagai berikut: $\mathrm{Y}=$ $2.024+0.339 \mathrm{X}_{1}+0.174 \mathrm{X}_{2}$, dimana Variabel Discount Price $\left(\mathrm{X}_{1}\right)$ mempunyai pengaruh yang dominan terhadap Impulse Buying pada Swalayan Alfamart Kota Bakti. Indeks korelasi sebesar $62.8 \%$ yang menunjukkan adanya hubungan kuat. Indeks determinasi diperoleh sebesar $39.5 \%$ yang berarti bahwa varisi variabel bebas dapat menjelaskan variabel tidak bebas sebesar $39.5 \%$ sedangkan selebihnya yaitu $60.5 \%$ dipengaruhi oleh variabel lain yang tidak diteliti dalam penelitian ini.Variabel Discount Price $\left(\mathrm{X}_{1}\right)$ dan Strategi Lokasi $\left(\mathrm{X}_{2}\right)$ secara simultan berpengaruh secara signifikan terhadap Impulse Buying pada Swalayan Alfamart Kota Bakti. Hal ini ditunjukkan oleh nilai $\mathrm{F}_{\text {hitung }} 30.336>$ $F_{\text {tabel }}$ 3.094. Variabel Discount Price $\left(\mathrm{X}_{1}\right)$ secara parsial berpengaruh signifikan terhadap Impulse Buying pada Swalayan Alfamart Kota Bakti karena nilai $\mathrm{t}_{\text {hitung }} 5.780>\mathrm{t}_{\text {tabel }} 1.986$. Variabel Strategi Lokasi $\left(\mathrm{X}_{2}\right)$ secara parsial berpengaruh signifikan terhadap Impulse Buying pada Swalayan Alfamart Kota Bakti. Hal ini ditunjukkan oleh nilai thitung 3.007 > $t_{\text {tabel }} 1.986$.

\section{Saran}

Berdasarkan hasil penelitian dan kesimpulan di atas, maka penulis menyarankan beberapa hal, antara lain

1. Discount price dapat meningkatkan impulse buying sehingga diharapkan agar pihak manajemen Swalayan Alfamart Kota Bakti memanfaatkan hal tersebut untuk menarik minat konsumen berbelanja dan meningkatkan penjualan. 
2. Diharapkan agar pihak manajemen Swalayan Alfamart Kota Bakti dapat menentukan lokasi yang strategis untuk menjaring konsumen lebih banyak lagi.

3. Diharapkan agar produk yang disediakan betul-betul berkualitas sehingga konsumen merasa aman dan nyaman berbelanja pada Swalayan Alfamart Kota Bakti.

\section{DAFTAR PUSTAKA}

Alma, B. 2010. Manajemen Pemasaran dan Pemasaran Jasa. Alfabeta. Bandung.

Arifianti, Ria. 2011. Pengaruh Atribut Supermarket Terhadap Impulse Buying (Survey Pada Supermarket Di Kota Bandung). Jurnal Pendidikan Manajemen Bisnis, Vol 9 No 17 1-75.

Belch, George E. dan Belch, Michael A. 2012. Advertising and Promotion: An Integrated Marketing Communication Perspective. 8th Edition. New York: McGraw Hill.

Cahyorini, A. dan Rusfian, E.Z. 2011. The Effect of Packaging Design on Impulsive Buying. Journal of Administrative Science \& Organization, Vol. 18 No. 1, hlm. 11-21.

Ghozali, Imam. 2013. Aplikasi Multivariate dengan program SPSS edisi ketujuh. Badan Penerbit. Semarang.

Gross, D. 2010. Fundamentals of Queueing Theory. John Willey and Sons. New York.
Isnaini, A. 2013. Model dan Strategi Pemasaran. NTP Press. Makasar.

Iqbal, Mohammad, 2011, Analisis Kinerja Sistem Pendekatan Teori dan Praktek, Perorhit Gunadarma, Depok.

Kasmir. 2014. Manaj

Perbankan. Jakarta: Prenada Media.

Kotler, P. dan Keller, K. L. 2012. Manajemen Pemasaran. Terj. Benyamin Molan. Indeks. Jakarta.

Levi, D.S. , Philip Kamin Sky dan Edith Simchi Levi. 2014. Designing and Managing The Supply chain : Concept,Strategies And Case Studies. Singapore : Irwin McGraw-Hill.

Ma'ruf, Hendry. 2016. Pemasaran Ritel. Gramedia. Jakarta.

Mc Carthy, E.J. dan W. D. Pereault. 2010. Pemasaran Dasar. Salemba Empat. Jakarta.

Mowen dan Minor. 2010. Perilaku Konsumen. Erlangga. Jakarta.

Park, Chung-Hoon, and Young-Gul Kim. 2015. "The Effect of Information Satisfaction and Relational Benefit on Consumers Online Site Commitmennts". Journal of Electronic Commerce in Organizations, Vol. 4, No. 1, Page $70-90$.

Pradhana, I.P.D. dan D. A. Martini. 2018. Pengaruh Personal 
Selling, Price Discount dan Bonus Pack Program Terhadap Perilaku Impulse Buying Konsumen Produk Oriflame pada PT. Orindo Alam Ayu di Kota Denpasar. Jurnal Ilmiah Manajemen dan Bisnis Volume 3, No.1. ISSN: 2528-2077.

Prihastama, Brian. 2016. Pengaruh Price Discount Dan Bonus Pack Terhadap Impulse Buying Pada Pelanggan Minimarket (Studi Pada Pelanggan Minimarket Indomaret $\mathrm{Jl}$. Demangan Baru, Depok, Sleman, Yogyakarta). Fakultas Ekonomi. Universitas Negeri Yogyakarta.

Rachma Nurmasarie dan S. Setyo Iriani. 2013. Pengaruh Promosi Penjualan dan Penjualan Perseorangan terhadap Keputusan Belanja Tidak Terencana. Jurnal Ilmu Manajemen Vol. 1 No. 2.

Rook, D dan Fisher, J.R. 2013. Normative Influences on Impulsive Buying Behaviour", Journal of Consumer Research, Vol. 22 (3), pp. 305-313.

Saladin. 2013. Manajemen Pemasaran. Analisis Perencanaan Pelaksanaan dan Pengendalian. Linda Karya. Bandung.

Schiffman, L.G. and Kanuk, L.L., 2012. Purchasing Behavior. Upper Saddle River, NJ: Pearson Prentice Hall.

Siregar, Syofian. 2013. Statistik Parametrik untuk Penelitian
Kuantitatif. Jakarta : PT. Bumi Aksara.

Sugiyono. 2014. Metode Penelitian Kuantitatif Kualitatif dan $R \& D$. Alfabeta. Bandung.

Sunyoto, Danang. 2014. Sistem Informasi Manajemen. Penerbit CAPS. Yogyakarta.

Sutabri, Tata. 2012. Sistem Informasi Manajemen. Penerbit Andi. Yogyakarta.

Sutisna. 2012. Perilaku Konsumen dan Komunikasi Pemasaran. Edisi kedua. Remaja Rosdakarya. Bandung.

Suwarman, U. 2010. Perilaku Konsumen Teori dan Penerapannya. Alfabeta. Bandung.

Syahrum, Salim. 2012. Metode Penelitian Kuantitatif. Cipta Pustaka. Bandung.

Tjiptono, Fandi. 2012. Strategi Pemasaran. Andi. Yogyakarta.

Utami, C.W. 2010. Manajemen Ritel. Salemba Empat. Jakarta.

Verplanken, B., Herabadi, A.G., Perry, J.A. and Silvera, D.H. 2011.Consumer style and health: the role of impulsive buying in unhealthy eating. Psychology and Health, Vol. 20, pp. 429-41.

Walukow, A.L., L. Mananeke, dan J. Sepang. 2014. Pengaruh Kualitas Produk, Harga, Promosi dan Lokasi terhadap 
Jurnal Sains Riset (JSR)

p-ISSN 2088-0952, e-ISSN 2714-531X

http://journal.unigha.ac.id/index.php/JSR

DOI. 10.47647/jsr.v10i12

Keputusan Pembelian

Konsumen di Bentenan Center

Sonder Minahasa. Jurnal

EMBA Vol. 2 No.3. ISSN 2303-1174.

Wathani, Fikrah. 2012. Perbedaan

Kecenderungan
Impulsif Produk Pakaian

Ditinjau dari Peran Gender.

Skripsi Strata I Program Studi

Ilmu Komunikasi, Universitas

Sumatera Utara. 